\title{
Origen y utopía. \\ Perspectivas sobre la construcción del mundo ideal \\ en Occidente y su fundamentación en las teorías \\ sobre el origen del mundo y el hombre. Modelos bíblico, clásico grecolatino y capitalista
}

Origins and Utopia. Perspectives on the Construction of an Ideal World in the West and its Groundings on Theories of the Origins of World and Man. Biblical, Graeco-Latin and Capitalist Models

\author{
Cossette Galindo Ayala \\ Instituto de Investigaciones Filológicas \\ Universidad Nacional Autónoma de México
}

\begin{abstract}
RESUMEN: En el presente artículo se intenta dar una visión panorámica de las cosmologías, antropogonías y utopías en las tradiciones bíblica y clásica grecolatina, anotando sus diferencias bajo el punto de vista de la hermenéutica cultural, al hacer referencia a la teoría Atenas y Jerusalén de Lev Shestov, la crítica de la filosofía de la historia de Karl Lowith, el análisis de los mitos del comienzo y del fin propuesto por P. Ricoeur y la historia de la filosofía de S. Pániker. Finalmente, abriremos una reflexión sobre la utopía de consumo de la sociedad capitalista mediante la crítica de la misma por parte de Erich Fromm.
\end{abstract}

ABSTRACT: In the present paper, we'll intent to give an overview of the mythological cosmogenesis, anthropogenesis and utopias inside the Biblical and classical Greco-roman traditions, stressing their differences within the context of cultural hermeneutics, in reference to Athens and Jerusalem theory held by Lev Shestov, the philosophy of history critic developed by Karl Lowith, Paul Ricoeur's analysis of myths of end and beginning, as well to S. Pániker's history of philosophy. Finally, will intent to open a discussion over the critic of the capitalism utopia sustained by Erich Fromm.

PALABRAS ClAVE: hermenéutica cultural, cosmogonía, antropogonía, escatología, utopía. KEYWORDS: cultural hermeneutics, cosmogony, anthropogenesis, eschatology, utopia. RECIBIDO: 16 de febrero de 2015 - ACEPTADO: 19 de marzo de 2015 
Cossette Galindo Ayala

Instituto de Investigaciones Filológicas

Universidad Nacional Autónoma de México

\section{Origen y utopía. Perspectivas sobre la construcción del mundo ideal en Occidente y su fundamentación en las teorías sobre el origen del mundo y el hombre. Modelos bíblico, clásico grecolatino y capitalista}

Es generalmente aceptado que lo que ha sido comprendido como el orbe occidental tuvo como fuentes de su construcción tanto la cultura bíblica, como la cultura grecolatina. Estas dos fuentes plantearon una interpretación de la realidad no sólo distinta, sino, en aspectos fundamentales, contradictoria. Una vez que el mundo de la Biblia entró en contacto con la civilización helenística durante la conquista de Palestina por Alejandro Magno a comienzos del s. IV a.C., inició también la marcha de un sincretismo entre un modelo de vida religioso y un modelo de vida filosófico que aún hoy es difícil de resolver y sobrellevar. Se trata del prolongado debate entre fe y razón, o como declararía Lev Shestov en Athenas and Jersualem, de la contradicción entre una actitud impasible ante el reinado de la necesidad y el destino, o de una confiada actitud ante lo que se considera una fuerza divina capaz de intervenir en la vida humana. Dicho sincretismo y el consiguiente dilema al cual conduce es también señalado por Karl Lowith cuando expone las fuentes centrales de la filosofía de la historia en Occidente:

El hombre moderno vive todavía del capital de la Cruz, y el círculo, de cristianismo y antigüedad; y la historia intelectual del hombre occi- 
dental es un continuo intento para reconciliar revelación con razón. Este intento nunca ha tenido éxito y nunca pasará de simple compromiso. Nietzsche y Kierkegaard han demostrado que la decisión inicial entre cristianismo y paganismo sigue siendo decisiva, porque ¿cómo se podrá reconciliar la teoría clásica de que el mundo es eterno con la fe cristiana en la creación; el ciclo con un eschaton, y la aceptación pagana de la fatalidad con el deber cristiano de la esperanza? Ello es irreconciliable, porque la concepción clásica del mundo es una concepción de cosas visibles, mientras que la cristiana es, después de todo, no una concepción, sino materia de esperanza y fe en cosas invisibles (Lowith 1956: 187-188).

En el presente trabajo iremos haciendo una revisión comparativa de las cosmogonías y antropogonías que propulsaron una visión utópica, es decir, la visión de un mundo ideal, tanto dentro de las tradiciones judía y cristiana, como clásica grecolatina, destacando sus similitudes y diferencias. Finalmente, haremos una observación sobre la situación más reciente de la utopía capitalista y la manera en que ha devenido en un ideal de consumo y hedonismo, desarticulado de cualquier tipo de propuesta ética.

Si algo resulta peculiar en la tradición judía respecto a otras cosmogonías del mundo cultural antiguo, no es precisamente la descripción sobre aquello que existía en el principio de los tiempos, sino el hecho de que hubiese existido un principio, es decir, que se hubiera cimbrado un momento en el cual, de no haber nada, ${ }^{1}$ se diera paso a la Creación. En el Génesis, el tiempo y la Creación se inauguran conjuntamente o, mejor dicho, la sustancia de la Creación es el tiempo mismo. Al crear Dios la luz y apartarla de la oscuridad (Gn 1, 3), el día y la noche nacen, y con ellos, el primer día que inaugura una escala de siete días primordiales. La totalidad del mundo y del hombre son presentados como una historia que cuenta con un principio y, por tanto, también con un final: "Ni el mundo ni el ser humano son eternos, sólo Dios lo es" (von Rad 1977: 60). Respecto a la creación del hombre, según narra el relato yahvista $(J)^{2}-$ que data del s. X-IX a. C.- , en un momento Yahvé crea los

1 Hay que destacar que la versión ex nihilo no es de cuño totalmente hebreo, pues su emergencia se produce en la época helenística.

2 La partición clásica del Pentateuco establece cuatro fuentes principales: el Yahvista 
cielos, los astros, la tierra, los mares, las especies vegetales y animales y finalmente un jardín en donde da forma al hombre a partir del cieno y un soplo divino inspirado en sus narices. En ese jardín situado en Edén, Dios hace brotar "el árbol de la vida" y "el árbol de la ciencia del bien y del mal", advirtiendo al hombre de la posibilidad de comer todos los frutos, excepto del fruto del árbol de la ciencia. El Creador encuentra que el hombre está solo y requiere una ayuda adecuada, por lo que hace caer a Adán en un profundo sueño, durante el cual le extrae una costilla con la que da forma a la mujer (Gn 2, 5-25). De acuerdo con el documento sacerdotal (P) $(\mathrm{Gn} 1,26)$ - s. VI a. C.-, 'Elohîm decide crear al ser humano, "hembra y macho", a "imagen suya", ${ }^{3}$ proveyéndolo de alimento gratuito con el cual subsistir sin otra misión más que gobernar sobre las criaturas circundantes. Posteriormente, al transgredir la prohibición a causa de la seducción que la serpiente ejerció sobre Eva y comer del árbol del conocimiento del bien y el mal, se dice que los ojos de ambos se abrieron y se dieron cuenta de que estaban desnudos, sintiendo vergüenza. Entonces Dios interpeló a Eva y la condenó a parir con dolor, mientras a Adán le impuso obtener el alimento con fatiga. Debido a que la pareja había llegado a ser "como los dioses", es decir, conocedores del bien y el mal, Dios decide expulsarlos del jardín del Edén y poner bajo custodia de querubines el camino hacia el árbol de la vida (Gn 3,1-24). Éste es el inicio de la experiencia del trabajo y del acto de parir como padecimientos. Dado que el pecado de Adán y Eva y la subsiguiente expulsión del Paraíso asocian el trabajo y la procreación como eventos dolorosos, la Historia de las generaciones humanas tiene como sello de inicio una condenación que ha de ser subsanada. La palabra tôledôt (generaciones) adquiere en la Biblia el significado

(J) y el Elohista (E), antiguos documentos tradicionales del siglo IX y vIII a. C.; la tradición Deuteronómica (D), que se desarrolla mayoritariamente durante el s. VII a. C., y el documento o código Sacerdotal (P) del período exílico o post-exílico (ss. VI-V a. C.).

3 Según la nota de la Biblia de Jerusalén a este pasaje, el término imagen (̌̌elem) implica parecido físico, como el de Adán con relación a su hijo. En relación con Dios, esta semejanza implica la distinción del ser humano para con los animales. Supone además una semejanza general de naturaleza. Ser imagen y semejanza de Dios subraya el hecho de que, al estar dotado de inteligencia y de voluntad, puede entrar activamente en relación con Dios. Para otros exegetas, sin embargo, el ser humano sería imagen de Dios porque recibe del Él dominio sobre los demás seres vivos. 
de Historia o, como explica Claus Westermann, en el judaísmo la genealogía es la forma más temprana de cronología (Westermann 1987). En este sentido, la Historia humana misma constituye un gran signo de separación de Dios, lo que hace que en ella lata, en cada generación, la expectativa de un restablecimiento de la armonía primigenia.

Según el orden secuencial de la Biblia, el relato de la Caída constituye el principio de la Historia primaria de la humanidad. Pero el credo israelita propiamente dicho, como religión de una comunidad específica entre otras, surge a partir de un acontecimiento histórico fundamental: la huida de Egipto y la marcha por el desierto. En el momento en que Dios revela su nombre y Ley a Moisés, Yahvé actuará en el curso de los acontecimientos históricos como signo y señal de la Alianza que mantiene con su pueblo elegido. Algunos estudiosos han comprendido la forma en que la Creación fue exaltada en muchos de los salmos como el primer acto soteriológico ofrecido por Yahvé a su pueblo. Surgen así las analogías centrales entre el devenir cósmico y la Historia de Israel. Así como la Creación será la primera demostración de una alianza entre Dios y el hombre, la tierra prometida a Moisés será el signo por el cual Yahvé establece una alianza con su pueblo. Sucede de este modo, explica Gerhard von Rad, porque el acontecimiento teológico que funda la antigua religión israelita había sido la experiencia de cautividad y liberación, y sólo después se antepuso el relato que habla de la Creación del mundo y el hombre (von Rad 1972: 170-171). Sin embargo, este último sentido cósmico y universal no será nunca del todo concretado en la vida judía, pues siempre se antepondrá la preeminencia de Israel, precisamente en su diferenciación de entre los pueblos del mundo. Cada generación y cada justo que esta generación veía nacer constituían un capítulo algo distinto del precedente, una manera de revelarse Dios en los acontecimientos históricos mediante un suspenso constante.

En tiempos de crisis, a causa de las sucesivas opresiones imperiales sobre la comunidad de Israel, la pérdida de confianza en la acción de Dios en la Historia hacía que la pregunta por aquel origen perdido descrito en el Génesis, en el que Dios cohabitaba con el hombre en el Paraíso, fuese transitando a la pregunta por el final de los tiempos. La escatología judía se nutre tanto de la idea de una tierra que será devuelta al pueblo de Israel, como signo de liberación y elección entre 
las otras naciones, como de la idea de una nueva Creación y una Tierra que será purificada del mal y nuevamente bendecida por Dios para que en ella habite una generación justa de elegidos. Entre la nostalgia del principio y la utopía de un fin de los tiempos, el hombre judío demostraba su vulnerabilidad ante un porvenir insospechado y la búsqueda por recobrar un estado de plenitud y unidad con Dios que se suponía originario. Encontramos en Job 15, 7-8, una referencia a lo que puede ser una versión anterior al relato del Paraíso: “¿Has nacido tú el primero de los hombres?/¿Se te dio la luz antes que a las colinas?/¿Escuchas acaso los secretos de Dios?/¿Acaparas la sabiduría?”, en donde Adán habría asistido a la asamblea divina y, ambicioso de una gloria mayor, habría robado la sabiduría, a la manera de Prometeo, realizando por impulso propio lo que la serpiente y Eva le inducen a hacer de acuerdo con el mito del Génesis (Graves 2000: 92). El hombre tenía en su seno la imagen de un origen perdido, de la Tierra perdida, la tierra de Edén. ${ }^{4}$

El tema del origen nos conduce también al del misticismo pues éste, bajo muy diversos simbolismos, ha significado el anhelo y tal vez la experiencia misma de recuperar una unidad primigenia que se supone perdida, ya sea unidad con el Cosmos, la Naturaleza o Dios. En su expresión formal, el misticismo judío ha variado considerablemente a lo largo de un proceso de interpretación constante, pero ha demostrado mantener como fondo invariable eso que Rudolf Otto explica como el reflejo subjetivo que infunde la presencia de lo Numinoso y que designa como sentimiento de creatura, el cual genera en el individuo una experiencia de absoluto anonadamiento, de no ser más que polvo y ceniza, como una forma de extrema dependencia para con esa fuerza que tiene el poder de vivificar pero también de aniquilar. Tal parece que es sólo frente al misterio inefable del Creador que nace y cristaliza el sentimiento de creatura en su pureza originaria (Otto 1980).

La tradición judía conocida como mística de la Merkavah (carro de Dios) hunde sus raíces en una experiencia portentosa, acogida en la soledad de una conciencia herida por el Exilio en Babilonia y luego de haber sufrido una de las mayores tragedias en la Historia del pueblo

4 Se trataría de la región situada entre el Tigris y el Éufrates, es decir, de la ciudad entre ríos: Mesopotamia. 
de Israel: la destrucción del Templo ${ }^{5}$ en el año 587 a. C. por orden del emperador neobabilonio Nabucodonosor. Desterrado a orillas del río Quebar en Babilonia, el profeta Ezequiel (Ez 1) contempla la presencia de Dios (Šehinah) en el espacio, sin ayer ni mañana, como imagen de un trono que flota ya sin morada donde aposentarse. Aquella visión de la Gloria de Dios ( $k a b o d$ ), podríamos pensar, fue la demostración de que la presencia divina trascendía el espacio material del Templo. Según los últimos capítulos del libro de Ezequiel, que se supone fueron agregados por la familia de los sacerdotes asmoneos, se exigía la construcción de una nueva Jerusalén y un nuevo Templo. Efectivamente, una vez que los judíos pudieron retornar a su tierra, más de medio siglo después, el Templo fue reconstruido y el culto reactivado. Sin embargo, dicha reedificación significó un completo cambio de poderes. Fueron los sacerdotes quienes se adjudicaron el gobierno del Templo bajo el auspicio del actual emperador persa y no de la monarquía de línea davídica anterior. Esto generó importantes crisis dentro de la comunidad judía y movimientos que intentaron deslegitimar el poder sacerdotal del Templo, bajo su descalificación como Templo impuro y exaltando la imagen mítica de una Creación renovada. Son tiempos en los que se redactan los primeros apocalipsis (siglo III a. C.) a manos de sectores del judaísmo para quienes la Historia había dejado de ser expresión de lo prometido por Dios - es decir, la soberanía de Israel en su Tierra - y el mundo no sólo había perdido la bendición divina, sino que se encontraba en posición antagónica para con el Creador. La visión pesimista de un mundo corrompido, despojado de la presencia y sabiduría divinas, harán más urgente que nunca la utopía de una nueva Creación y una nueva era bendecida por Dios. Así, dentro de algunos escritos apocalípticos, el fin de los tiempos viene a significar el advenimiento de una era gloriosa en la que Dios, directamente o a través de un mesías preexistente (Hijo del hombre), triunfará para salvar a los justos cuando la historia se derrumbe.

Si atendemos a la manera en que Salomón construyó el Templo (1 Rey 6,38), cada uno de los motivos de la decoración como flores, hojas de palmera, querubines, todo cubierto de oro, intentaban reflejar el esplendor del jardín del Edén cuando Dios habitaba conjuntamente con el hombre. Este simbolismo reflejaba la perfecta armonía entre Dios y su creación mediante el reinado de David. 
Simbólicamente, los apocalipsis judíos, los escritos que describen las cosas últimas, guardan una correspondencia estrecha con los escritos que describen las cosas primeras (Glasson 1961: 74 y ss.). Como una suerte de búsqueda por reingresar al Paraíso, la escatología apocalíptica se alimentó del mito del origen hasta completar el cuadro de la era mesiánica. Sin embargo, los términos del principio (Urzeit, tiempo del principio) y del fin (Endzeit, tiempo del final) nunca llegarían a ser idénticos, pues, para la mentalidad judía, la Historia sería siempre esa mediación irreductible en la que la conciencia ética de la que participaba Israel simbolizaba el camino específico de perfeccionamiento que Dios había marcado a su pueblo. Como aclara decisivamente Karl Lowith, entre otros autores, la concepción particular de Israel como pueblo elegido de Dios es la única donde religión e historia pueden converger de forma insoslayable:

El hecho excepcional de la existencia judía pudo significar una inteligencia estrictamente religiosa de la historia política, porque sólo los judíos son un pueblo realmente histórico, constituido como tal, por la religión, mediante el acto de la revelación del Sinaí. De ahí que el pueblo judío pudo, y aún pueda en verdad, entender religiosamente su historia y destino nacionales como una unidad política-religiosa. [...] La posibilidad de la creencia en el ordenamiento providencial de los destinos históricos del mundo depende de esta creencia en un pueblo sagrado de importancia universal, porque sólo los pueblos, no los individuos, son los sujetos propicios de la Historia, y únicamente un pueblo sagrado está relacionado directamente con el Señor, como el Señor y disponedor de la Historia (Lowith 1956: 220).

Los apocalipsis incluyen también la llamada escatología personal, que no se contemplaba en el judaísmo normativo. Este tema aparece en numerosos lugares de la literatura apocalíptica bajo la idea del Infierno que aguarda a las almas de los malvados o del Reino de Dios que espera a las de los justos y humildes, tras el Juicio Final. En esta literatura, al igual que en ciertos pasajes midráshicos, se habla de Enoc como el primer hombre que entró vivo en el Paraíso en donde contempló el árbol de la vida, bajo cuya sombra descansa Dios, y de cuyas raíces brotan los cuatro ríos de donde mana leche, miel, vino y aceite. ${ }^{6} \mathrm{Y}$ tal como

6 Se admite de forma generalizada que el germen del misticismo judío se encuentra en la siguiente parábola rabínica: 
aparece en algunos textos apócrifos, el Paraíso se sitúa en el tercer Cielo y no en la Tierra (Graves 2000: 86). Este incipiente desarrollo de la noción de alma individual, propio de la literatura apócrifa del período intertestamentario, es precisamente una de las fuentes que darán origen al credo cristiano como una noción de salvación individual y, por tanto, universal. Karl Lowith da cuenta de esta diferencia respecto al judaísmo estricto:

En la concepción cristiana, la historia de la salvación ya no está limitada a una nación determinada, sino que se ha internacionalizado por haberse individualizado. La historia de la salvación se refiere a la salvación de las almas, individualmente consideradas, con abstracción completa de su condición política, racial y social; y la contribución de las naciones al Reino de Dios se mide por el número de elegidos, no por logro o fracaso alguno de la comunidad (Lowith 1956: 221).

Hay que poner en claro entonces que la escatología apocalíptica difiere de la escatología profética judía tradicional en el punto de comprender la Era Mesiánica como apertura más allá de la historia, así como la salvación, ya no sólo en términos del pueblo elegido, sino del destino del alma individual tras la muerte. El cristianismo nació de lo que conocemos como período intertestamentario, donde muchas de las ideas judías tradicionales se modificaron bajo el clima intercultural de época helenística.

Respecto al modelo grecolatino, Karl Kerényi (1994: 17-43) nos ofrece una revisión de las teorías antropogónicas anteriores a la visión clásica

\footnotetext{
“Cuatro entraron al Jardín (Pardés): Ben Azay, Ben Zoma, Ajer y Rabí Aquiba.

Uno echó una mirada y murió.

Otro echó una mirada y se volvió loco.

Otro echó una mirada y cortó los tallos.

Y uno subió en paz y bajo en paz.

Ben Azay echó una mirada y murió. A él se refiere el versículo: Preciosa es a los ojos del Señor la muerte de sus santos (Sal 116, 15).

Ben Zoma echó un vistazo y perdió la razón. De él dice la Escritura: Si has hallado miel come sólo lo que necesitas (Proverbios 25, 16).

Elisa echó un vistazo y cortó los tallos. De él dice la Escritura: No permitas que tu boca te induzca a pecar (Qohelet 5,5).

Rabí Aquiba subió en paz y bajó en paz. De él dice la Escritura: Llévame en pos de ti. Corramos. Me ha introducido el Rey en sus cámaras (Cantar de los Cantares 1, 4)" Haguigá 2, 3-4 (citado en Laenen 2006: 9).
} 
de la Edad de Oro griega y la "feliz convivencia de dioses y hombres", en donde la concepción del hombre no es todavía la de un civilizado, es decir, del agricultor, sino que se trata de la criatura humana en su más primaria condición como brote o mera rebaba de la tierra. Esta imagen, señala Kerényi, "constituye el contrapeso científico de las representaciones oníricas del paraíso" (Kerényi 1994: 18-20). Así pues, la primera versión del hombre primitivo coincide con la teoría evolucionista en el sentido de que trata del hombre como una criatura que "brota de la tierra", como una criatura incompleta.

La imagen de la originaria Tierra no se reduce a una mera representación científica de barro fértil, pues contiene el mito de la diosa Gea o Gaia, la tierra que bajo los pies de los hombres los determina por su filiación. Esta tradición, conocida como de la autoctoneidad, permanece, aunque ya no porte su antiguo significado religioso. La palabra latina homo se relaciona con humus "tierra", en griego XӨஸ́v (cthón=tierra), $\mathrm{y}$ alude a ese mismo mitologema en donde la tierra era la madre originaria. La narración mitológica sobre el advenimiento de la agricultura y los misterios eleusinos, como un don de la diosa Deméter, según cuenta el himno homérico, presupone la existencia del mundo de los héroes. En una versión que se ha considerado protoórfica (s. v a. C), aparece Disaules, con sus características primigenias preagrícolas, un autóctono sobre el campo todavía en barbecho, quien acoge a Deméter mientras ésta busca a su hija. Su nombre indica que posee una granja miserable, una vivienda pobre y humildes rebaños. En agradecimiento, Deméter le otorga una doble bendición: la agricultura y los misterios de Eléusis. Esta versión tiene la significación de mostrar cuán dura era la vida del hombre antes de recibir los dones de Deméter cuando todavía era imperfecto, es decir, no iniciado. En otros poemas órficos y pitagó-

7 Lucrecio (n. 99 a. C m. 55 a. C) es quien presenta esta imagen, considerándosele precursor y estímulo de la interpretación evolucionista del hombre primitivo. Sin embargo, aun cuando la versión de Lucrecio (De rerum Natura, Libro V) alude al hombre prehistórico, se trata ya de una composición de cuño mitológico. Y es así porque la tierra es puesta en paralelo con la figura de la madre: "Resta sólo admitir que la tierra merece el nombre de madre, puesto que todo ha sido creado de ella. Todavía ahora surgen de la tierra muchos animales, engendrados por las lluvias y la cálida emanación del sol; por lo que es menos extraño que nacieran aún más y de mayor corpulencia cuando eran jóvenes la tierra y el éter" (vv. 795-800). 
ricos tardíos encontramos el mismo prejuicio sobre el hombre como un ser incompleto: "Y las inútiles estirpes de los mortales, carga de la tierra, criaturas semejantes a sombra, no suficientemente listos para percatarse del infortunio inminente, ni para eludir las consecuencias del mal, ni para volverse hacia lo bueno y saber qué hacer cuando aparece, sino ignorantes, inútiles, nada previsores..." (Kerényi 1994: 35-36).

Esquilo, precursor de Epicuro y Lucrecio, presenta en su Prometeo la misma predicación contra el estado primitivo de la humanidad, esto es, contra los no iniciados, inmersos en una imperfección culpable y superable, a la manera de un in-acabamiento. Ni en Hesíodo ni en Esquilo aparece Prometeo como participante en la primera fase de la creación humana, pues ésta se concibe como un "brotar de la tierra". El relato de Esquilo parte de ese mismo estado de autoctoneidad en el que no había fuego y pone en labios de Prometeo el mismo prejuicio sobre los hombres antes de que él los completara:

Pero oídme las penas que había entre los hombres y cómo a ellos, que anteriormente no estaban provistos de entendimiento, los transformé en seres dotados de inteligencia y en señores de sus afectos. Hablaré, aunque no tenga reproche alguno que hacer a los hombres. Sólo pretendo explicar la benevolencia que había en lo que les di. En un principio, aunque tenían visión, nada veían, y, a pesar de que oían, no oían nada, sino que, igual que fantasmas de un sueño, durante su vida dilatada, todo lo iban amansando al azar. No conocían las casas de adobes cocidos al sol, ni tampoco el trabajo de la madera, sino que habitaban bajo la tierra, como ágiles hormigas, en el fondo de grutas sin sol (Kerényi 1994: 38-39).

Encontramos así el esquema en donde la Diosa madre de la primera fase es la Tierra, creadora de una vida animal, profana e imperfecta. En la segunda fase aparece Deméter como Diosa madre, quien otorga la perfección y la iniciación a través de los cereales, vinculados al enigma de sus misterios. Los hombres primitivos de la mitología griega son en parte individuos, como el Disaules eleusino, el Pelasgo arcádico, el Alcomeneo beocio, y en parte son grupos daimónicos, como los Curetes ideos y los Coribantes frigios, los Cabiros, quienes aparecen en vasijas en forma de enanos embrionarios y exageradamente fálicos,

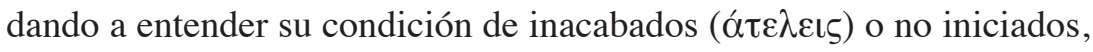


asemejándose a los Dáctilos ideos, criaturas enanas surgidas de la tierra, asociadas con el trabajo de los metales y el manejo del fuego, de naturaleza ígnea, sirvientes y compañeros de la gran Diosa Rea o Deméter. Representan al verdadero hombre primitivo, autóctono de forma pura, tal y como fue originalmente concebido.

Lo central en este mitologema es la concepción, no sólo griega, de que para devenir hombre a partir del protohombre (hombre primitivo) es necesaria una segunda formación, creación o nacimiento. Esta segunda formación era, para los griegos, la santificación a través del pan y los Misterios, donde la civilización alude tanto a esta formación como a la agricultura. El hombre que proviene de la tierra se convierte en hombre solamente en la segunda fase de la creación por medio de un acabamiento demetérico o prometeico.

Según nos explica Ernst Robert Curtius, la tradición de una Edad de Oro y del locus amoenus, propias de la lírica pastoril, recoge de la poesía homérica la glorificación del mundo, la tierra y el hombre en la que todo está gobernado por fuerzas divinas:

Los poetas posteriores toman del paisaje homérico varios motivos que después se convierten en patrimonio estable de una larga cadena de tradiciones: el lugar encantado de eterna primavera, escenario de la vida bienaventurada de más allá de la tumba; el paraje placentero, con su árbol, su fuente, su prado; el bosque poblado de diversas especies de árboles; la alfombra florida. [...] En Homero y toda la poesía antigua, la naturaleza aparece siempre habitada, sin que difiera el paisaje habitado por dioses del ocupado por hombres (Curtius 1955: 267-268).

La Arcadia de los poetas clásicos como Teócrito o Virgilio, así como del Quattrocento italiano, con Petrarca y Bocaccio como exponentes, no es precisamente la cruda naturaleza en su curso exuberante y a veces peligroso, es más bien la naturaleza suavizada por la cultura, ese paisaje ameno en el que todo está predispuesto y obedece a las leyes de la cortesía (Morábito 1995). Es, de algún modo la reproducción artificial del origen paradisíaco, bajo la mirada nostálgica o utópica de aquel que busca un orden ideal en el que naturaleza y cultura convivan en perfecta armonía. Pero, tal como explica el escritor Fabio Morábito, en este mundo idílico en el que no hay lugar para la corrupción, el dolor o la 
necesidad, la vivencia nunca llega a transformarse en una experiencia de maduración:

Todo lo que pasa, ya lo dijimos, les pasa por primera y última vez. Y lo que define la sustancia de toda aventura es el hecho de ocurrir por primera y única vez, fuera de las regularidades cotidianas. Los pastores viven en un continuo asombro. Son unos amantes volubles porque la devoción y la fidelidad sólo pueden aparecer cuando también aparecen la costumbre y la experiencia; con ellas, de hecho, comienza la intimidad. Por el contrario, la aventura elimina el contacto, o lo reduce a algo instantáneo o deslumbrante (Morábito 1995: 68).

Para el mundo grecolatino, la idea de una Edad dorada, donde la tierra y los hombres gozan de un esplendor primaveral perenne, y donde el gobierno de la Justicia ha triunfado, es una utopía que se encuentra estrechamente vinculada al espacio del campo, los pastores y a ese tiempo que borrará el efecto de, cual pecado original, la "maldad primera". Así, la célebre Égloga IV de Virgilio (40 a. C.) es un himno de esperanza sobre el retorno del reino de Saturno y Rea, y donde la figura del Mesías pagano es encarnada por Salonino, hijo del Emperador:

Lo que ay de la maldad nuestra primera

Deshecho, quedarán ya los humanos

Libres de miedo eterno y de ansia fiera.

Mezclado con los dioses soberanos,

De vida gozará, qual ellos, llena

De bienes deleitosos y no vanos,

Verálos, y verán su suerte buena,

Y del valor paterno rodeado

Quanto se estiende el mar, quanto el arena.

(Égloga IV, vv. 25-33)

Retomando la imagen de la utopía dentro de la literatura apocalíptica, la distinguimos del locus amoenus grecolatino en el punto en el que las condiciones históricas que determinan al hombre, es decir, la procreación y el trabajo, si bien se dan en una atmósfera de plenitud y abundancia, no están del todo eliminadas. Al menos así lo testifican las imágenes de la Tierra 
prometida en algunos apocalipsis judíos como es el Libro de los Vigilantes (s. III a. C.), perteneciente al Libro primero de Enoc:

Entonces serán humildes todos los justos, vivirán hasta engendrar mil hijos, y cumplirán en paz todos los días de su mocedad y vejez. En esos días toda la tierra será labrada con justicia, toda ella quedará cuajada de árboles y será llena de bendición. Plantarán en ella toda clase de árboles amenos y vides, y la parra que se plante en ella dará frutos en abundancia. De cuanta semilla sea plantada en la tierra una medida producirá mil, y cada medida de aceitunas producirá diez tinajas de aceite (1 En 10, 17-11) (Piñero 2010: 100).

Ciertamente, en los escritos apocalípticos, la imagen del Reino Mesiánico, que espera a los justos tras el Juicio Final, no excluye la experiencia del trabajo, del envejecimiento y la muerte. Pues, recordemos, el encadenamiento de las generaciones (tôledôt) es para el mundo judío lo que siembra una exigencia moral y ética a lo largo de una línea temporal, jamás del todo borrada, ya que significa a la vez la esencia de su identidad como comunidad histórica.

Dentro del cristianismo, la noción del Reino de Dios, no es, como hemos visto, la expectativa de una consumación histórica, tal como lo entiende el judaísmo tradicional, sino que se comprende como una realidad invisible y consumada, que, sin embargo, espera su revelación para cumplirse plenamente más allá de la historia. Esta visión, que san Agustín ilustra como la Ciudad de Dios, opuesta a la Ciudad de los hombres, es la utopía que también acontece en la interioridad de la experiencia mística del alma cristiana individual. En la medida en que el Reino de Dios se concibe, a través de la predicación evangélica cristiana, como una metáfora de la interioridad, la utopía se convierte en un destino del alma que, en la soledad del eremita o del asceta, supondrá la muerte del yo mundano para nacer a la vida nueva en unión con Dios. Y es este sentido interior y atemporal, propio de la mentalidad cristiana, el que ha predominado en la cultura occidental. De esta manera, el origen puede comprenderse como un estado del ser más que del tiempo. La preciada unidad del ser, tan buscada por la filosofía clásica, llega, no obstante, a un punto límite en la visión de Emmanuel Levinas (y que, suponemos, emana de la impronta rabínica que a él le caracteriza), donde la plenitud 
ontológica, y la soledad de la existencia que ella supone, es rebasada por la socialidad: "En realidad, el hecho de ser es lo más privado que hay; la existencia es lo único que no se puede comunicar; yo puedo contarla, pero no puedo dar parte de mi existencia. La soledad, pues, aparece aquí como el aislamiento que marca el acontecimiento mismo de ser. Lo social está más allá de la ontología” (Levinas 1991: 55).

El concepto del tiempo que Europa había heredado de su matriz judía fue continuado por la filosofía una vez que el hombre creyó emanciparse de los dioses. Apoyada en el pensamiento de Hegel, la utopía de Occidente se había trasladado, ya desde hacía tiempo, de la visión de un Reino de Dios al campo del progreso científico y técnico ilimitado. La "religión del progreso" como ideal de un perfeccionamiento futuro de la sociedad diverge, entonces, necesariamente de la idea cristiana de salvación. ${ }^{8}$ Como lo expresa María Zambrano, el sentido de la trascendencia se traslada a la acción del hombre en una suerte de deificación de la Historia humana sin más: "Y así, vino a surgir esta divinidad extraña, humana y divina a la vez: la historia divina, mas hecha, al fin, por el hombre con sus acciones y padecimientos. [...] Deidad entera como depositaria del espíritu absoluto, deidad a medias porque, como los dioses paganos, estaba creada, configurada por el hombre" (Zambrano 1955: 17).

Tanto para la tradición bíblica como para la clásica grecolatina, el “origen de los tiempos", como idea de un Paraíso primordial o como la Era de Saturno respectivamente, es un estado donde la acción pecaminosa del hombre en la Historia o bien, las tribulaciones y cansancios del trabajo en la Era de Júpiter, no han sido aún conocidos. Como hemos visto, de acuerdo con la profecía virgilina, la plenitud humana se contempla como un "retorno" de la Era Saturno. Es así porque para los paganos, la Historia humana, al igual que la Naturaleza, cumple con un estricto orden de auge, decadencia y renacimiento. Sin embargo, para la concepción judía, la profecía del Reino de Dios no significa

8 Como observa Karl Lowith, la idea cristiana de salvación sólo anuncia un único elemento de transformación, y que es independiente de la historia: "Lo que pregonan los Evangelios no es un mejor futuro de nuestra condición terrenal, sino el súbito advenimiento del Reino de Dios, contrapuestos al existente reino de los hombres [...]. La salvación no será alcanzada por un desarrollo gradual de nuestras facultades naturales, sino mediante una transformación decisiva de la naturaleza pecadora del hombre" (Lowith 1956: 127). 
precisamente un retorno al Paraíso primordial, sino una culminación definitiva, donde la humanidad es resarcida por la acción mesiánica, no a la manera de un retorno a la inocencia perdida, más bien como intervención misericordiosa de Dios y como recompensa de una acción ética por parte de los "justos y elegidos" que han resistido a todo lo largo de la Historia Sagrada.

Sigmund Freud logró establecer el análisis de la cultura mediante la yuxtaposición de símbolos traídos del análisis psicológico. Partiendo de esa arqueología del sujeto, que es el deseo inconsciente, Paul Ricoeur intentó una especie de simbolización total al añadir la hermenéutica de la fenomenología del espíritu de Hegel, en la que el sentido estaría también en su proyección como finalidad y no sólo en los orígenes del sujeto, como en Freud:

El psicoanálisis nos proponía una regresión hacia lo arcaico; la fenomenología del espíritu nos propone un movimiento según el cual cada figura encuentra su sentido, no en aquella que la precede, sino en la que le sigue; así, la conciencia es arrastrada fuera de sí, delante de sí, hacia un sentido puesto en marcha, en el cual cada etapa es abolida y retenida en la siguiente. De este modo, una teleología del sujeto se opone a una arqueología del sujeto (Ricoeur 2003: 25).

En la crítica que Ricoeur realiza sobre el psicoanálisis, considera a éste no como hermenéutica parcial en su objeto, sino en sus presupuestos metodológicos, a saber, desde el exclusivo punto de vista del modelo tópico-económico y el modelo genético (Ricoeur 2003: 134), sin explorar lo que en la dinámica regresiva y progresiva surge como valor nиеvo (arte, mito, religión), constituido de forma consciente en otra esfera que supera la mera repetición de lo reprimido. Ciertamente, la ilusión que sublima las pulsiones de muerte y vida que operan en el individuo de forma inconsciente se proyecta en modelos culturales como la creación de obras artísticas, sedimentados en el tiempo, e impidiendo que el ejercicio se repita idéntico. Así, podemos observar por qué, pese a que el judaísmo se funda, según Freud, en el recuerdo traumático de un parricidio, primero de Yahvé contra Atón (faraón egipcio) y posteriormente de Moisés contra Yahvé, logra generar, en cada ejercicio de retorno y superación mediante la ilusión, un nuevo punto de partida en 
la espiral progresiva de la Historia Sagrada. De esta manera, se puede entender que aun cuando se mantenga el recuerdo de un acontecimiento primordial, la ilusión proyectada en obras concretas, la tradición y la reinterpretación de la tradición constituyen un intervalo que separa el principio del fin. La contrapartida de ese apego narcisista a la madre o al origen que se da en el inconsciente como deseo sería la creación consciente de obras que van quedando en el tiempo como cicatriz, pero a la vez liberación de la fatalidad de nuestros complejos. Tal como la vida individual se distiende entre los polos de un arkhé y un télos, la Historia de la humanidad se tensa entre la concepción de un origen y un fin, una cosmogonía y una escatología, un génesis y un apocalipsis, un origen y una utopía.

De ahí que la escatología apocalíptica, aunque establece un paralelismo entre las condiciones del principio (Urzeit) y del fin (Endzeit), demostrando la analogía entre la hermenéutica del inconsciente y la hermenéutica de la consciencia, no permite que se establezca una identidad completa entre ambos polos, pues es el excedente de sentido acumulado en la Historia ética de la comunidad lo que promueve el punto de partida desde un campo cada vez distinto, donde el acontecimiento es sublimado en una esfera heterogénea a la del comienzo. Quizá podemos decir que la Historia avanza en la medida en que conserva el recuerdo de una acción arquetípica originaria, que impide el olvido de lo reprimido, pero, a la vez, acumula un "capital" extra de sublimación que se proyecta en las instancias objetivas de la cultura y que atraen la conciencia, tanto como lo hace el trauma hacia el pasado, hacia una plenitud futura.

Análogamente, Salvador Pániker nos ofrece un modelo para comprender la importancia que el origen, lo real, o bien, lo místico, tiene en el despliegue de la filosofía como punto de partida y como finalidad simultáneamente. Se trata del avance retroprogresivo que da cuenta de la Historia de la filosofía como un inicial distanciarse del origen para recuperarlo en los albores de la filosofía post-moderna. La razón instaura una problematicidad que se efectúa sobre la realidad no-problemática del origen que, como un límite, es precisamente la condición de posibilidad del lenguaje y, por tanto, de la razón crítica. Como lo indica Pániker, la esencia de la mitología órfica, complementaria de la teogo- 
nía de Hesíodo, consistiría en ese intento, a través de un rito de muerteresurrección, de recobrar el origen pensado como no-dualidad, unidad de todas las cosas vivas, y que va en contra de la separación entre los hombres y los dioses. "El retroprogreso se define por un movimiento hacia la parcelación y fragmentación de lo real, y un contramovimiento de recuperación de la no-dualidad originaria" (Pániker 1992: 42).

De acuerdo con Ricoeur, lo sagrado significa el alpha en la arqueología y el omega de la teleología, como fundamento que interpela al hombre y que se anuncia como aquello que dispone de su existencia (Ricoeur 2003: 26). Para María Zambrano, lo sagrado es el fondo último, la realidad misma, de la que el hombre va extrayendo a sus dioses, dándoles forma y función y, de este modo, ganando un tiempo o espacio vital (Zambrano 1980: 135). Lo sagrado sería lo ambiguo y ambivalente por carecer de tiempo, lo inescrutable, el arcano que sin embargo es fundamento del origen y del fin, tanto del individuo como de la Historia humana. Pero "tener a donde ir", dice Zambrano, es vivir, y es mediante la aparición de los dioses de entre la saturación de lo sagrado como la humanidad pudo comenzar a andar. Proceso, camino, vía, son algunas de las figuras a las que recurrimos para expresar que el hombre ha de cumplir el periplo de la separación de su origen, para dibujar una espiral distinta de la inicial. La Historia, dice Zambrano, "es la dimensión por la cual la vida es trágica, constitutivamente trágica y ser persona es rescatar la esperanza, venciendo, deshaciendo la tragedia" (Zambrano 1980: 246-255). Somos ese tiempo que reniega de sí mismo, trágicamente, en búsqueda de una raíz desconocida. Desconocida, sí, porque la conciencia misma abre la grieta que rompe la continuidad del ser con su origen.

Este límite es precisamente aquel que libera al sujeto de esa nostalgia o anhelo por la totalidad, que en la filosofía ha marcado un enfoque que pasa por alto la irreductible y misteriosa presencia del otro:

En efecto, es toda la marcha de la filosofía occidental, culminando en la filosofía de Hegel, la cual, muy justamente, puede aparecer como la culminación de la filosofía misma. Por todas partes, en la filosofía occidental, donde lo espiritual y el sentido residen siempre en el saber, puede verse esa nostalgia de la totalidad. Como si la totalidad hubiese sido per- 
dida, y esa pérdida fuese el pecado del espíritu. La visión panorámica de lo real es entonces la verdad y lo que da toda su satisfacción al espíritu. [...] La experiencia irreductible y última de la relación me parece, en efecto, que está en otra parte: no en la síntesis, sino en el cara-a-cara de los humanos, en la socialidad, en su significación moral. Pero hay que comprender que la moralidad no se añade como una capa secundaria, por encima de una reflexión abstracta acerca de la totalidad y sus peligros; la moralidad tiene un alcance independiente y preliminar. La filosofía primera es una ética (Levinas 1991: 71).

Efectivamente, la enajenación por lo ideal resulta devastador para la realidad de los procesos sociales, la diversidad que implica un largo camino de diálogo con el otro y de compromiso con la Historia. Así, la imagen utópica, en su perfección, puede llegar a convertirse en la causa de una alienación, pues al no existir la distancia y la diferencia de donde el diálogo surge, se parece más a un reino totalitario que a un jardín lleno de dicha. Podría decirse que la Arcadia constituiría una especie de principio del placer en el que no existe separación entre el yo y el mundo, entre el deseo y su cumplimiento. Tal como expresa Levinas: "El totalitarismo político reposa sobre un totalitarismo ontológico. El ser sería un todo. Ser en el que nada acaba y en el que nada comienza. Nada se opone a él y nadie lo juzga. Neutro anónimo, universo impersonal, universo sin lenguaje" (Levinas 1991: 74).

La necesidad nos da indicios de una unidad posible, ya sea inscrita en el arkhé de nuestro inconsciente o proyectada en la utopía del Espíritu absoluto; y ha de ser, merced a la salud de los individuos y pueblos, una necesidad que alumbre sin llegar a incendiar la Historia y la biografía, el camino, la respiración humana. Esta respiración es precisamente el deseo de algo que no se concreta todavía. Emmanuel Levinas ha hecho clara la distinción entre necesidad y deseo: "He intentado describir la diferencia entre el Deseo y la necesidad por el hecho de que el Deseo no puede ser satisfecho; que el Deseo, de alguna manera, se alimenta de sus propias hambres y aumenta con su satisfacción; que el Deseo es como un pensamiento que piensa más de lo que piensa" (Levinas 1991: 87). Mientras que: "La necesidad se abre sobre un mundo que es para mí - retorna a sí - aunque sublime, como necesidad de la salvación, es todavía nostalgia, mal del retorno. La necesidad es el retorno mismo, 
la ansiedad del yo por sí, forma original de la identificación que hemos llamado egoísmo. Es asimilación del mundo tendente a la coincidencia consigo mismo o dicha" (Levinas 1991: 87).

De alguna forma, la utopía ha de ser oxigenada por la Historia, el camino de lo imprevisible que caracteriza al hombre y el lento aprendizaje a través de sus elecciones a lo largo del tiempo y en la relación con los otros. Ese Reino de Dios o esa Arcadia, ese futuro en el que el progreso humano logra su cumplimiento, y que han imaginado los hombres embargados por la nostalgia o la esperanza, son tal vez la demostración de una mayor resistencia a convivir con lo divino, pues como dice Zambrano:

Absorber totalmente a lo divino es una forma de querer librarse de ello. Y entonces no queda espacio para el trascender del que no tiene nada que ligar, puente sin orillas en que tenderse. No tiene nada entre que mediar; realidad e irrealidad; ser y no ser, lo que ya es con el futuro sin término, pues que todo pretende ser real de la misma manera. La pretendida divinización del hombre y de la historia produce la misma asfixia que debió existir cuando, allá en tiempos remotos, el hombre no alcanza a hallar puesto bajo el sol en el espacio lleno de dioses, de semidioses, de demonios (Zambrano 1980: 260-261).

Porque el amor, si bien es anhelo de unidad, "delirio divino" según es descrito en el Fedro y el Banquete - "camino que sube por grados de éxtasis hacia el origen único de todo lo que existe, lejos de los cuerpos y de la materia, lejos de lo que divide y distingue, más allá de la desgracia de ser uno mismo y de ser dos en el amor mismo" (Rougemont 1993: 63) - , no puede existir más que en la distancia y la diferencia que abre el tiempo. Tal como expresa Levinas, en el amor, la alteridad no sólo es un atributo de una diferencia, es el atributo central de la naturaleza de aquel a quien se ama:

En el extremo opuesto del conocimiento, que es supresión de la alteridad y que, en el 'saber absoluto' de Hegel celebra la 'la identidad de lo idéntico y de lo no-idéntico', la alteridad y la dualidad no desaparecen en la relación amorosa. La idea de un amor que sería una confusión entre dos seres es una falsa idea romántica. Lo patético de la relación erótica es el 
hecho de ser dos, y que el otro es en ella absolutamente otro (Levinas 1991: 62).

El amor surge precisamente del horizonte, de la frontera que separa y a la vez comunica lo ideal y lo real, los dioses y los hombres, aquello que nace de la lejanía, lo que da perspectiva a la mirada que, de otro modo, se convertiría en la ausencia de mirada, la contigüidad homogénea de un reino totalitario. Como ha hecho ver Emmanuel Levinas, el tiempo es justamente lo que invalida la idea de una totalidad y un yo cerrado, pues el otro surge con el tiempo, "como si el otro fuera la trascendencia, fuera, por excelencia, la abertura al otro y a lo Otro" (Levinas 1991: 54). Tal vez el gozo humano no radique en escapar del tiempo sino en celebrarlo, y con ello, también celebrar la libertad. Porque la libertad, al igual que el amor, es una manera de tomar perspectiva, de andar en un cuestionamiento sin saber, es decir, es lo que nos hace ser humanos.

Tanto para el mundo judaico y cristiano como para el mundo grecolatino, la construcción de una utopía estaba en relación con la huella de un estado de plenitud originaria perdida que, sin embargo, difería considerablemente. Como hemos mencionado antes, la mística judía consiste en la revelación de Dios como Creador y en el sentimiento de creatura, mediante el cual el hombre recupera las condiciones originales del Paraíso. Como explica Zambrano, el ser no es, dentro de la concepción bíblica, en última instancia "resultado de un esfuerzo y de una elección, sino de haber sido engendrados y elegidos, pues ser en forma natural es ser como hijo" (Zambrano 1980: 314). Por su parte, la Arcadia de la Edad de Oro pagana expresa un mundo ideal en el que las cualidades humanas son divinizadas en el sentido de ser perfeccionadas e ilimitadas. La concepción de la plenitud bíblica no va más a allá de la recuperación del sentimiento de filiación para con el Creador, mientras que la plenitud clásica se basa en la concepción de una perfección sobrehumana. En este sentido, podría decirse que la imagen del Paraíso bíblico es la de una perfecta filialidad o dependencia, mientras que la imagen grecolatina es la de una perfecta autosuficiencia.

Entre la imagen de una utopía como plenitud del ser, sin devenir, sin perspectiva, y la Historia como escenario en el que padecemos la incertidumbre de nuestras preguntas y el resultado de nuestras elecciones, 
es posible buscar una vía que conduce a la verdadera intimidad con lo real, el equilibrio entre el dentro asfixiante del útero, que nos libera del padecer, y el afuera amenazador, yendo hacia la convivencia, una vida en la que la Historia sería alentada por la utopía y la utopía se pondría en movimiento a través de la Historia.

Hoy por hoy, parece que el sistema de consumo tiene su propia utopía, que es el ideal del hedonismo por sobre el compromiso con el futuro de las generaciones y el respeto a la Naturaleza. Erich Fromm detecta el surgimiento de esta utopía hedonista en los albores de la sociedad capitalista:

Desde el siglo XVIII se han desarrollado muchas teorías éticas: algunas fueron formas más respetables del hedonismo, como el utilitarismo; otras fueron sistemas estrictamente antihedonistas, como los de Kant, Marx, Thoreau y Schweitzser. Sin embargo, en la época actual, en general desde el fin de la primera Guerra Mundial, se ha regresado a la práctica y a la teoría de un hedonismo radical. El concepto de un placer ilimitado forma una extraña contradicción entre la aceptación de la ética de un trabajo obsesivo y el ideal de pereza completa durante el resto del día y las vacaciones. Por una parte, la línea de ensamble interminable y la rutina burocrática, y por otra, la televisión, el auto y el sexo, forman una combinación contradictoria (Fromm 1978: 24).

Lo que impera es la ilusión de suprimir el tiempo y la Historia mediante paraísos mediáticos y publicitarios, lugares en donde buscamos negar el devenir, la procreación, el envejecimiento y la muerte. Erich Fromm ha elaborado detalladamente una crítica de la sociedad de consumo mediante la oposición tener/ser, y en donde la obsesión por tener está decididamente fundamentada en la negación de la muerte: "La necesidad de tener posee otro fundamento: el deseo biológico de vivir. Seamos felices o infelices, nuestro cuerpo nos impulsa a esforzarnos por la inmortalidad; pero por experiencia sabemos que moriremos y buscamos soluciones que nos hagan creer que, a pesar de la evidencia empírica, somos inmortales" (Fromm 1978: 87-88).

Lo curioso del modelo utópico de consumo es que no parece tener un origen localizable o consistente. En lugar de eso parece que este modelo se basa en una mentira radical, lo que ni el hombre ni la naturaleza son. 
Los modelos utópicos que dieron origen a la civilización occidental y que hemos revisado en este trabajo contemplaban la idea de un estado de plenitud para la humanidad fundamentados en una idea de armonía primigenia del hombre con la Creación o la Naturaleza. No obstante, para el modelo de consumo, el escenario original no existe porque se trata de un modelo donde el ser humano ha sido desplazado o se ha deshumanizado en favor del culto a la tecnocracia y las máquinas, por lo que la Naturaleza ya no es contemplada en una relación de armonía, sino de explotación, según lo describe Erich Fromm:

Hemos tratado de resolver nuestro problema existencial renunciando a la visión mesiánica de la armonía entre la humanidad y la naturaleza, y al conquistar a la naturaleza, al transformarla para nuestros fines, su conquista se ha convertido, cada vez más, en equivalente de destrucción. Nuestro espíritu hostil y de conquista nos ciega al hecho de que los recursos naturales tienen límites y pueden agotarse, y que la naturaleza luchará contra la rapacidad humana (Fromm 1978: 26).

En las postrimerías de la modernidad, donde el modelo humanista tradicional está fuera de consideración, en favor de un régimen tecnocrático cada vez más avasallante cuyo origen es insustancial, quizás debamos beber en las fuentes bíblicas y clásicas para comprender claramente la "filosofía religiosa" que proponía Lev Shestov, o bien, apuntar de forma decidida hacia un nuevo origen.

\section{Bibliografía}

Biblia de Jerusalén (1980). Bilbao, Desclée de Brouwer.

Curtius, Ernst Robert (1955). Literatura europea y Edad Media latina. México, Fondo de Cultura Económica.

Fromm, Erich (1970) La revolución de la esperanza. México, Fondo de Cultura Económica.

- (1978). ¿Tener o ser? México, Fondo de Cultura Económica.

Glasson, Francis (1961). Greek Influence in Jewish Eschatology. London, SPCK.

Graves, Patai (2000). Los mitos hebreos. Madrid, Alianza. 
KERÉNYI, Karl ( I994). "Hombre primitivo y misterio", Círculo Eranos 1. Barcelona, Anthropos, pp. 17-43.

Laenen, J. H. (2006). La mística judía. Madrid, Trotta.

Levinas, Emmanuel (I99I). Ética e infinito. Madrid, Antonio Machado Libros.

Lowith, KARL (I956). El sentido de la historia. Implicaciones teológicas de la filosofía de la historia. Madrid, Aguilar.

Morábito, Fabio ( I 995). Los pastores sin ovejas. México, Conaculta.

Отто, Rudolf ( I980). Lo santo. Lo racional y lo irracional en la idea de Dios. Madrid, Alianza.

PÁniker, Salvador (i992). Filosofía y mística. Una lectura de los griegos. Barcelona, Anagrama.

Piñero, Antonio (20io). Apócrifos del Antiguo y del Nuevo Testamento. Madrid, Alianza.

RAD, Gerhard von (I972). Teología del Antiguo Testamento II. Salamanca, Sígueme.

Ricoeur, Paul (2003). El conflicto de las interpretaciones. Buenos Aires, Fondo de Cultura Económica.

Rougemont, Denis de (i 993). Amor y Occidente. México, Conaculta.

Virgilio (200 I). "Églogas”, en fray Luis de León, Poesías completas. Obras propias en castellano y en latín y traducciones e imitaciones latinas, griegas, bíblico hebreas y romances. Madrid, Castalia.

Westermann, Claus (1987). Genesis. Edinburgh, Wm. B. Eerdmans Publishing, T\&T Clarck.

Zambrano, María ( I 955). El hombre y lo divino. México, Fondo de Cultura Económica. 